\title{
Teaching Aids Effectiveness in Learning Mathematics
}

\author{
Shwan H. H. Alshatri ${ }^{1}$, Karzan Wakil2, Kazhal Jamal ${ }^{3}$, Ribwar Bakhtyar ${ }^{4}$
}

\section{ARTICLE INFO}

Article History:

Received 03.01.2019

Received in revised form

05.04.2019

Accepted

Available online 01.07.2019

\begin{abstract}
Teaching Aids (TA) are those accessories, tools, and items used by the classroom teacher to assist students in understanding the concepts of the lesson. In other word, Using a TA is to explain the lesson efficiently so that the students can grasp the lesson idea and messages efficiently. There are many types of TA whereas considering student grade levels, corresponding interests and abilities for selecting any type have a great impact on student engagement beyond a traditional lecture format. This study aims to examine the effects of the use of different teaching aids (visual, audio and audiovisual)in teaching Mathematics in the primary schools especially in grade 7 to 9 . This study uses the descriptive method on the cadastral form. The results showed that the preferred teaching aids are audiovisual by rating $80 \%$, compared to the other two teaching aids which are visual and audio by rating $6 \%$ and $14 \%$ respectively.
\end{abstract}

(C) IJERE. All rights reserved

Keywords:

Teaching Aids, primary school, educational mathematics.

\section{INTRODUCTION}

The science that deals with the arrangement, logic of shape and quantity. Math everywhere, all around us, in everything we do. It is the essential base for everything in our daily lives, including mobile devices, architecture (ancient and modern), art, money, engineering, and even sports. Since the dawn of recorded history, every enlightened society has been led by mathematic discovery, and in use in even the most primitive of cultures. The necessity of math correlated with social needs. The more complex a society, the more complex the mathematical needs (Hom, 2013).

Mathematics is a wide-spread material needed by the human being in his daily life and needs coordination and facilitate that student can pass it easily (Holton \& Artigue, 2001). Mathematics is a broad material in which full of rule and analysis that needs to be training, exercising and thinking. It should be testing the student's mind and thinking. It requires effort and fatigue and facilitates the understating level of the subject and treats the low level of student's knowledge in the face of the material. In this research we pay attention to Teaching Aids (TA) as a basic fundamental to get benefit from TA and take care of it, we have to pay attention, especially primary schools especially in the grade 7 to 9 .

As mentioned before, Mathematics is a building block for every science that student can learn it in schools and universities. Students usually have difficulties in learning mathematics due to math abstractness. Using Teaching Aids (TA) as a tool to help the instructor in explaining the lecture in the classroom. On the other hand, TA can help students to overcome their difficulties in learning math because TA makes the material of Mathematics become an interesting subject and students feel comfortable. Thus students can overcome the psychological problems, while they are studying so that they can grow their thinking then shows their potentials abilities. Eventually, an intelligent generation will be born that capable of answering that they faced in Mathematics. (Tonks, 2012).

\footnotetext{
1Shwan.hassan@charmouniversity.org, orcid.org/0000-0002-0157-110X, General Sciences Department, College of Medicals and Applied Sciences, Charmo University, Chamchamal 46023, Iraq.

2 karzan.wakil@spu.edu.iq, orcid.org/0000-0002-2513-1053, Research Center, Sulaimani Polytechnic University, Sulaimani 46001, Iraq

3Aliprice@yahoo.com, orcid.org/0000-0001-5433-2439, English Language Department, Institute of Training and Educational Development in Garmian, Kalar 46021, Iraq.

${ }_{4}^{4}$ Ribwar.ibrahim@spu.edu.iq, orcid.org/0000-0003-0287-0934, Information Technology Department, Technical College of Informatics, Sulaimani Polytechnic University, Sulaimani 46001, Iraq.
} 
Besides the traditional teaching methods, there are some teaching materials which can be used in the classroom that help students to learn and understand the lecture quickly and easily. Teaching materials are important catalysts of instructions; there are wide varieties of TA available to the teacher. They help students to improve studying and other skill. It makes lessons enjoyable and memorable(Ahmed, Clark-Jeavons, \& Oldknow, 2004). In this paper often called TA and called (Audio and visual). In which emphasis on visual via showing students some pictures through data show (projector). This research aims to determine the effectiveness of TA in the primary schools especially in grade 7 to 9 . The literature provides convincing evidence that TA in teaching Mathematics in the primary school is beneficial and has much significance (Ahmed et al., 2004; Musacchia, Sams, Skoe, \& Kraus, 2007; Raphael \& Wahlstrom, 1989; Sobel \& Maletsky, 1988).

In general, TA can help the teacher to facilitate a better understanding of the subject which discourages the act of confusion. It makes the subject and every aspect of the lesson very clear and makes them successful in learning Mathematics. It directly connects to the teacher's intelligent and influences their students. It is one of the wonderful teaching tools which is very convenient in the classroom, a teacher can involve students in the process of learning by doing some simple things like use of proper body language, eye contact with students, good facial expression, giving students time to talk, calling them by their names, etc. All these activities create a friendly learning atmosphere in the class and bridge the gap between teacher and students. A teacher can be a model, a narrator, singer, presenter, dancer, and friend and role like a player. By playing these roles in the classroom, a teacher can encourage the students to participate actively in the class. It will also keep them alert and learn efficiently.

In previous works, we found effective technology in teaching and learning in primary and high schools (Wakil, Qaisar, \& Mohammed, 2017), in this work we showed that enriching classroom by using new technology, the result of this research presented that the learning increased $22.9 \%$ after using technology for teaching inside classrooms. In another work, we found the side effect of electronic games on the students GPA (Wakil, Omer, \& Omer, 2017) when using games help students to think if they use it under control, but they decreased their GPA when used 1-3 hours per day by $-2.41 \%$. Also, it explained how ICT subject has a positive role in the Primary schools (Wakil, Muhamad, Sardar, \& Jalal, 2017) when exams the schools when studied ICT subject better evolved and increased teaching process compared with other schools. Moreover, we found effective Microlearning in the process learning(Mohammed, Wakil, \& Nawroly, 2018) this learning a new style of learning and memorizing information in students mind for long times. This paper tries to find the role of Teaching Aids in learning Mathematics in the Primary School. Moreover, in the recent works we presented the effectiveness of social networks on Students GPA (Wakil, Nasraddin, \& Abdulrahan, 2018), and The Effectiveness of Technology for Improving the Teaching of Natural Science Subjects in the primary schools (Nawzad, Rahim, \& Said, 2018). These previous works lead us to to finding best way for teaching another subjects like mathematics.

\section{THE ADVANTAGES OF TA}

The advantages of the TA as the following (Ahmed et al., 2004),

- Developing the level of the student's mind and thinking.

- Make students use these tools more.

- Keep all information in the mind students for a long time.

- Makes the student perform the activities on his / her own.

- Developing the students' mind.

- Give full understanding and accuracy of the lesson.

\section{TYPES OF TA}

There are many different types of TA that are very important in the learning process. 
1. Visual: It is one of the tools that students can grow the accurate image when the students see and hear properly (Giaquinto, 2007). For example, visual aids, movable image and includes all picture that moves, whiteboard, global or earth shows us the distance between two cities or countries and measurements; etc.

2. Audio equipment: One of the most important kinds of aids is audio: local radio school, speaker, microphone and radio (Kafyulilo, 2014).

3. Audiovisual: This is a modern tool for easy to understanding. Such as; animated film, Poster, Television, Video, Acting and theater, and so on (Musacchia et al., 2007).

In this paper we mention about some groups are related to the TA in teaching Mathematics as, field trip or excursion, the science exhibition, and the school exhibition.

Field trip: A journey by a group of people to a place away from their normal environment (Orion, 1993). The purpose of the trip is usually observation for education, non-experimental research or to provide students with experiences outside their everyday activities. They learn what they saw and will stay for a long time in their mind.

The science exhibition: Includes all activities that work in the school in which all teachers and students participated. This is an easy way to learn. There are following types of an exhibition:

1. Classroom gallery.

2. School show.

3. Exhibition at the level of the governorate.

4. Exhibition at the level of the state.

5. International exhibitions.

Types of the scientific boarding such as; chalkboard, priming board, pocket board, magnet board, electrical board, scientific board.

\section{METHODS}

Our methodology in this paper is the descriptive method on the cadastral form. In this research, fiftyfour teachers were invited to participate in a questionnaire-based study. Only fifty teachers completed the questionnaire, and their responses were analyzed. The first part of the questionnaire included the place of the teachers, so the second part consisted of gender. Also, the third part of this questionnaire is a level of study. Then the fourth part is marital status. Finally, we mention the grades of the students, as mention in Table 1.

Table 1. Participate in a Questionnaire Based Study.

\begin{tabular}{cccccccccccc}
\hline & Place & & \multicolumn{2}{c}{ Gender } & \multicolumn{2}{c}{ Level of study } & \multicolumn{2}{c}{ Marital status } & \multicolumn{3}{c}{ Classes } \\
\hline State & City & Town & Male & Female & Institute & University & Married & Unmarried & Grade & Grade & Grade \\
& & & & & & & & & 7 & 8 & 9 \\
25 & 15 & 10 & 23 & 27 & 27 & 23 & 33 & 17 & 16 & 16 & 18 \\
& Total: & & & 50 & & 50 & & 50 & & 50 & \\
& 50 & & & & & & & & &
\end{tabular}

The research community in the some of the primary schools at Sulaymaniyah state, Iraq.

\section{RESULTS:}

Example research consists of taking the opinions of Fifty (50) teachers in a group of different primary schools on TA in those classes that taught in grade 7 to 9 of the primary school. Using of TA which make the lesson easier to develop the level of students' thinking, love the material and convey much information in less time that was in yes and no question, mostly asked by participants. Table 2 shows the answers to participates for important questions in our survey. 
Table 2. Important questions to the participate in a questionnaire.

\begin{tabular}{clcccccc}
\hline No. & \multicolumn{1}{c}{ Questions } & Yes & $\begin{array}{c}\text { Yes } \\
\text { by } \%\end{array}$ & No & $\begin{array}{c}\text { No } \\
\text { by } \%\end{array}$ & $\begin{array}{c}\text { To some } \\
\text { extent }\end{array}$ & $\begin{array}{c}\text { To } \\
\text { some } \\
\text { extent } \\
\text { by } \%\end{array}$ \\
\hline Q1 & $\begin{array}{l}\text { Using of TA facilities Mathematics. } \\
\text { The use of TA helps to develop the level of }\end{array}$ & 37 & $74 \%$ & 3 & $6 \%$ & 10 & $20 \%$ \\
Q2 & $76 \%$ & 5 & $10 \%$ & 7 & $14 \%$ \\
Q3 & $\begin{array}{l}\text { Using TA help to keep students from forgetting } \\
\text { the lesson. }\end{array}$ & 34 & $68 \%$ & 7 & $14 \%$ & 9 & $18 \%$ \\
Q4 & $\begin{array}{l}\text { Using of TA makes lessons more enjoyable, and } \\
\text { students love the subject. }\end{array}$ & 40 & $80 \%$ & 1 & $2 \%$ & 9 & $18 \%$ \\
Q5 & $\begin{array}{l}\text { Using TA helps to get more information in less } \\
\text { time. }\end{array}$ & 35 & $70 \%$ & 4 & $8 \%$ & 11 & $22 \%$ \\
Q6 & $\begin{array}{l}\text { TA is an attractive and effective lesson by } \\
\text { students. }\end{array}$ & 40 & $80 \%$ & 2 & $4 \%$ & 8 & $16 \%$ \\
Q5 it struggle effective to learning Mathematics. & 38 & $76 \%$ & 1 & $2 \%$ & 11 & $22 \%$ \\
\hline
\end{tabular}

Above table presents the result of participates for each question. In the Q1, the question is "Using of TA facilities Mathematics" the participates returned yes by rating $74 \%$, for to some extent the rate is $20 \%$, and the rate of no is $6 \%$. But in Q2, the question is "The use of TA helps to develop the level of students' thinking or mind." the participates returned yes by rating $76 \%$, for to some extent the rate is $14 \%$, and the rate of no is $10 \%$. In the Q3, the question is "Using TA help to keep students from forgetting the lesson." the participates returned yes by rating $68 \%$, for to some extent the rate is $18 \%$, and the rate of no is $14 \%$. Also, in the Q4, the question is "Using of TA makes lessons more enjoyable, and students love the subject." the participates returned yes by rating $80 \%$, for to some extent the rate is $18 \%$, and the rate of no is $2 \%$. Then, in the Q5, the question is "Using TA helps to get more information in less time." the participates returned yes by rating $70 \%$, for to some extent the rate is $22 \%$, and the rate of no is $8 \%$.

Furthermore, in the Q6, the question is "The TA is an attractive and effective lesson by students." the participates returned yes by rating $80 \%$, for to some extent the rate is $16 \%$, and the rate of no is $4 \%$. The final question is "Is it struggle effectively to learning Mathematics." the participates returned yes by rating $76 \%$, for to some extent the rate is $22 \%$, and the rate of no is $2 \%$. As illustrated in Figure 1.

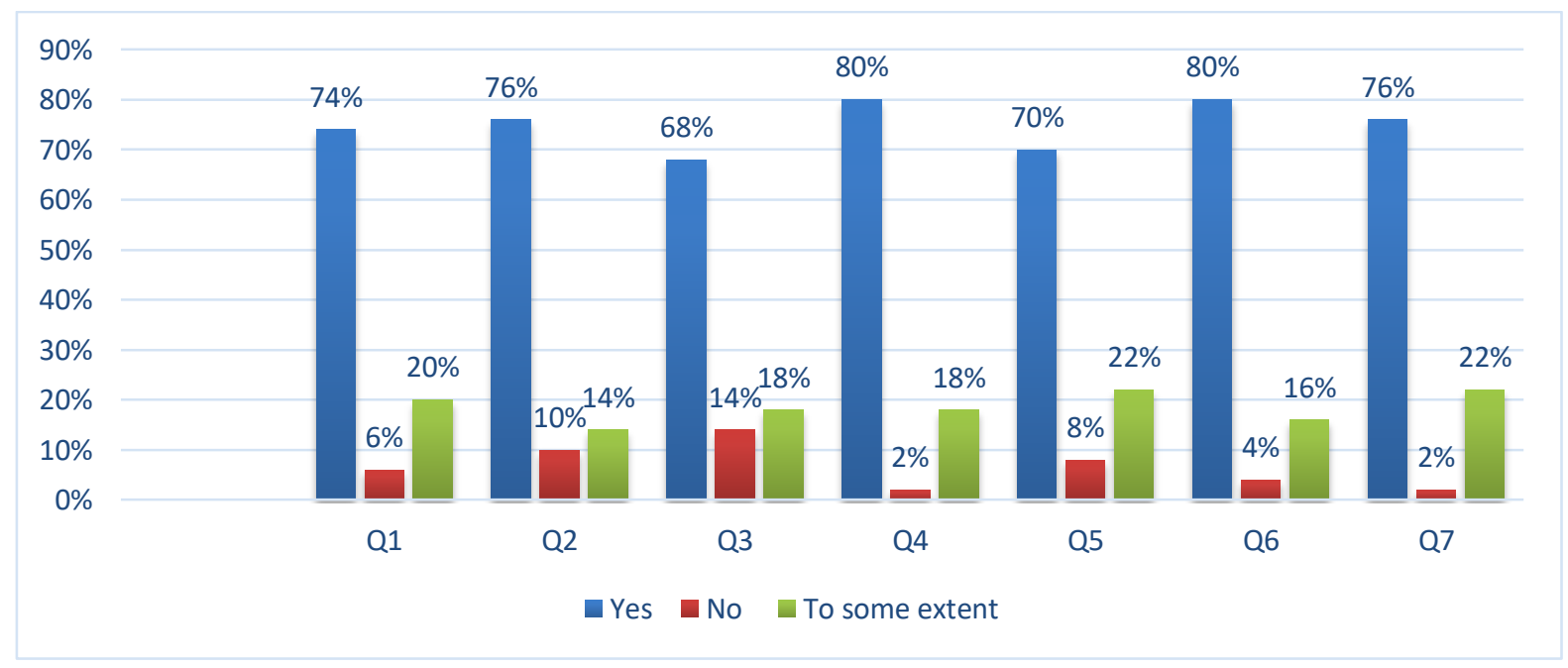

Figure 1. Bar chart of answers important questions from participations. 
In Figure 2 presented the important point that regards to the type of best method. Most of the participant (\%80) think that Audiovisual more important for understanding. But few of them think that Audio equipment and visual useful for understanding by rating $14 \%$ and $6 \%$ respectively.

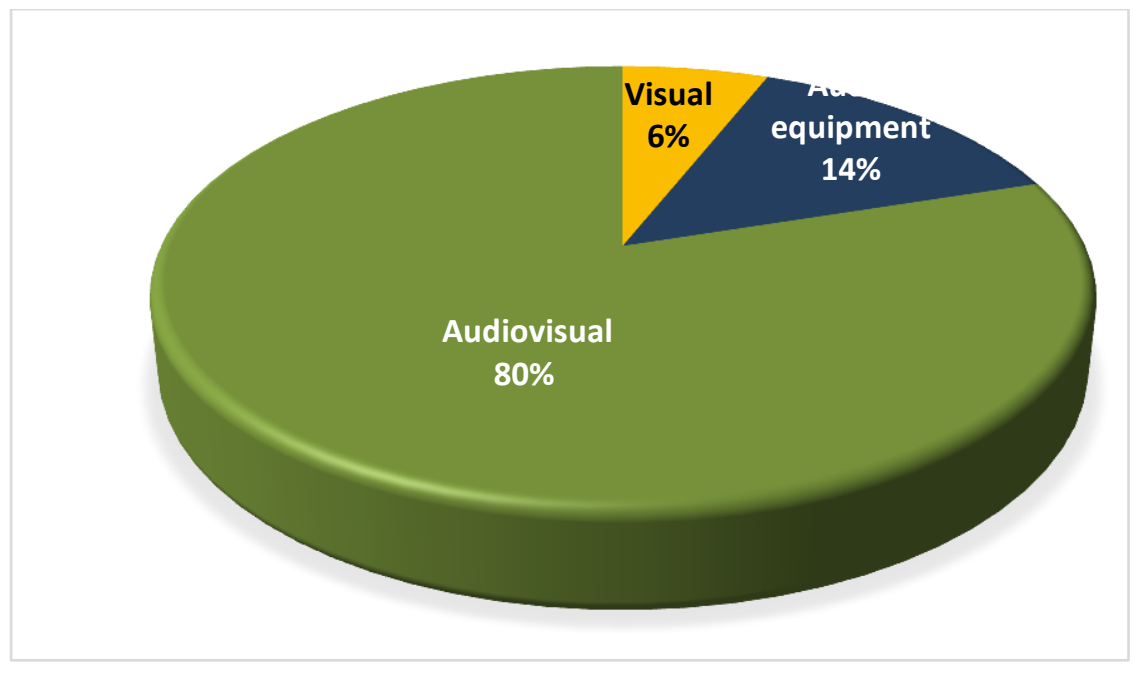

Figure 2. The best method of the TA is audiovisual.

\section{CONCLUSIONS AND FUTURE WORK}

Base on the results it is obvious that using TA is favorable. The method was used for this study is the descriptive method on the cadastral form. Using audiovisual TA leads to deliver more information to students by the teacher with less effort in a short time. Moreover, help students to overcome their struggle in learning mathematics and makes the lesson more interesting, attractive and effective in primary school for grade 7-9, during didactic lectures. The result of this paper can be enhanced and enriched by examining each of audio and video separately to achieve more detail info about the effectiveness of using TA, and the researchers can use more criteria and tools for evaluating student for Mathematics subject, also, they can inspect using technology like smart board, IPad and so on for teaching Mathematics in the classrooms.

\section{REFERENCES}

Ahmed, A., Clark-Jeavons, A., \& Oldknow, A. (2004). How can teaching aids improve the quality of mathematics education. Educational Studies in Mathematics, 56(2-3), 313-328.

Giaquinto, M. (2007). Visual thinking in mathematics: Oxford University Press.

Holton, D., \& Artigue, M. (2001). The teaching and learning of mathematics at university level: An ICMI study (Vol. 7): Springer Science \& Business Media.

Hom, E. J. (2013). What is Mathematics? Retrieved from What is Mathematics?

Kafyulilo, A. (2014). Access, use and perceptions of teachers and students towards mobile phones as a tool for teaching and learning in Tanzania. Education and Information Technologies, 19(1), 115-127.

Mohammed, G. S., Wakil, K., \& Nawroly, S. S. (2018). The Effectiveness of Microlearning to Improve Students' Learning Ability.

Musacchia, G., Sams, M., Skoe, E., \& Kraus, N. (2007). Musicians have enhanced subcortical auditory and audiovisual processing of speech and music. Proceedings of the National Academy of Sciences, 104(40), 15894-15898.

Nawzad, L., Rahim, D., \& Said, K. W. (2018). The Effectiveness of Technology for Improving the Teaching of Natural Science Subjects. Indonesian Journal of Curriculum and Educational Technology Studies, 6(1), 1521.

Orion, N. (1993). A model for the development and implementation of field trips as an integral part of the science curriculum. School Science and Mathematics, 93(6), 325-331.

Raphael, D., \& Wahlstrom, M. (1989). The influence of instructional aids on mathematics achievement. Journal for Research in Mathematics Education, 173-190. 
Sobel, M. A., \& Maletsky, E. M. (1988). Teaching mathematics: A sourcebook of aids, activities, and strategies: Prentice-Hall.

Tonks, D. (2012). Teaching aids: Routledge.

Wakil, K., Muhamad, D., Sardar, K., \& Jalal, S. (2017). The Impact of Teaching ICT for Developing Education Systems. International Journal of Advanced Research (IJAR), 5(7), 873-879. doi:10.21474/IJAR01/4793

Wakil, K., Nasraddin, R., \& Abdulrahan, R. (2018). The Role of Social Media on Students GPA. Indonesian Journal of Curriculum and Educational Technology Studies, 6(1), 1-5.

Wakil, K., Omer, S., \& Omer, B. (2017). Impact of Computer Games on Students GPA. European Journal of Education Studies.

Wakil, K., Qaisar, N., \& Mohammed, C. (2017). Enriching Classrooms with Technology in the Basic Schools. European Journal of Open Education and E-learning Studies. 